Research Article

\title{
Parametric Study of High-Efficiency and Low-Emission Gas Burners
}

\author{
Shuhn-Shyurng Hou and Ching-Hung Chou \\ Department of Mechanical Engineering, Kun Shan University, Yung-Kang District, Tainan City 71003, Taiwan
}

Correspondence should be addressed to Shuhn-Shyurng Hou; sshou@mail.ksu.edu.tw

Received 25 September 2013; Accepted 8 October 2013

Academic Editor: Shoou-Jinn Chang

Copyright ( $(2013$ S.-S. Hou and C.-H. Chou. This is an open access article distributed under the Creative Commons Attribution License, which permits unrestricted use, distribution, and reproduction in any medium, provided the original work is properly cited.

\begin{abstract}
The objective of this study is to investigate the influence of three significant parameters, namely, swirl flow, loading height, and semi-confined combustion flame, on thermal efficiency and CO emissions of a swirl flow gas burner. We focus particularly on the effects of swirl angle and inclination angle on the performance of the swirl flow burner. The results showed that the swirl flow burner yields higher thermal efficiency and emits lower $\mathrm{CO}$ concentration than those of the conventional radial flow burner. A greater swirl angle results in higher thermal efficiency and CO emission. With increasing loading height, the thermal efficiency increases but the $\mathrm{CO}$ emission decreases. For a lower loading height $\left(2\right.$ or $3 \mathrm{~cm}$ ), the highest efficiency occurs at the inclination angle $15^{\circ}$. On the other hand, at a higher loading height, $4 \mathrm{~cm}$, thermal efficiency increases with the inclination angle. Moreover, the addition of a shield can achieve a great increase in thermal efficiency, about 4-5\%, and a decrease in CO emissions for the same burner (swirl flow or radial flow).
\end{abstract}

\section{Introduction}

Much attention has been paid to higher thermal efficiencies and lower emissions of domestic gas burners since the everincreasing demand for energy saving and emission reduction [1-13]. As recognized, the domestic gas burner most extensively used is of the conventional Bunsen type (i.e., partially aerated) $[6,14,15]$. The typical partially aerated burner entrains primary air naturally by a momentumsharing process between the high velocity gas jet and the ambient air [6]. The most popular fuel used in domestic gas burners is liquefied petroleum gas (LPG), which is also used in this work. Typically, designs of conventional domestic gas burners are mainly relied upon open combustion flame such that energy loss through the dispersion of the flue gas to the surroundings is very large, resulting in relatively low thermal efficiency [13]. Clearly, if the dispersion of the flame or flue gas to the surroundings can be prolonged, then the thermal efficiency can be improved.

Heat and mass transfer are strongly influenced by swirl in a number of natural and technological flows [16]. It has been shown that swirl flow had great potential to lengthen the residence time and enhance mixing by means of the rotating flow field [10-13]. Swirl flows have been extensively used in many industrial furnaces and boilers as well as internal combustion engines as they can enhance mixing between fuel and oxidant and flame stabilization. However, most of the domestic gas burners are of nonswirl flow type, rather than swirl flow type. Therefore, in order to achieve high efficiency and low emissions, it is of great importance that the swirl flow in a domestic gas burner can be properly designed.

Recently, low-emission, energy-efficient gas burners have attracted much attention. However, there is still lack of studies on the flow type affecting burner performance, especially swirl flow. The objective of this study is to investigate the influence of swirl flow including swirl angle and inclination angle on the burner performance. Domestic gas burners with swirl flow are proposed by adjusting different values of swirl angle and inclination angle. Their thermal efficiencies and $\mathrm{CO}$ emissions characteristics will be discussed and compared with those of the convectional nonswirl flow burner. Furthermore, the influences of heating height (loading height) and semiconfined flame (shielded flame) on thermal efficiencies and $\mathrm{CO}$ emissions are explored. The results obtained herein 
would be helpful for us to understand what parameters govern burner performance and to provide significant design or operation concepts of domestic gas cookers in real applications.

\section{Experimental Setup and Method}

Figure 1 schematically illustrates the experimental apparatus. LPG contained in a steel cylinder is used as fuel, which consists of $40 \%$ propane and $60 \%$ butane by volume with a higher heating value of $114 \mathrm{MJ} / \mathrm{m}^{3}$. A wet-gas meter is used to measure the flow rate of LPG. Meanwhile, a U-tube manometer is employed to regulate the supply pressure of LPG, which can be adjusted by the pressure regulator. In this study, a double-ring gas burner, which consists of a burner head (see Figure 2(a)) and outer- and inner-ring burner caps (made of copper), is adopted. The flow rates of outer- and inner-ring burner caps can be separately controlled by means of their own mixing tubes.

The port design of gas burner is the primary factor greatly influencing the flow type and in turn dominating the burner performance (thermal efficiency and emissions). In the present work, we only change the outer-ring flow type (radial flow (nonswirl flow) or swirl flow with various swirl angles and inclination angles) but keep the inner-ring flow type (radial flow) and the other remaining components the same. This is because the outer-ring flow supplies the major heat source and mainly governs the burner performance. As shown in Figure 2(b), the outer-ring burner cap has 50 ports with the same diameter of $0.0028 \mathrm{~m}$ along their circumference. Their axes are designed to be oriented towards the horizontal plane of the burner at an inclination angle, $\beta$, and thus their tangential projections at a swirl angle, $\alpha$, with respect to the burner's radius can be generated. Accordingly, swirl flames can be formed in the outer-ring burner cap by supplying a primary air-LPG mixture through the burner ports. Figure 3(a) shows a typical rotating flame, which is produced by the flame jets emerging from the burner ports with swirl flow. Different values of swirl angle $(\alpha=26$, 36,46 , and $\left.56^{\circ}\right)$ and inclination angle $(\beta=10,15,20$, and $\left.25^{\circ}\right)$ are designed to access the influence of swirl flow on the burner performance. On the other hand, if $\alpha=0^{\circ}$, then the conventional nonswirl flow burner (radial flow burner) is formed (see Figure 3(b)).

In addition to swirl flow, we also examine the effects of adding a shield enclosing the burner on improving thermal efficiency and reducing $\mathrm{CO}$ emission. The circular shield is made of stainless steel sheet, whose height is $0.11 \mathrm{~m}$, inner diameter is $0.32 \mathrm{~m}$, and thickness is $0.0008 \mathrm{~m}$ (see Figure 4) [15]. The shield has 15212 round holes of $0.00155 \mathrm{~m}$ diameter. The semiconfined combustion flame (with the circular shield enclosing the burner) has a potential to suppress the dispersion of the high temperature flame and flue gas, resulting in higher thermal efficiencies. Therefore, comparisons of thermal efficiencies and $\mathrm{CO}$ emissions for the semiconfined and open combustion flames are made.

As shown in Figure 5, the sampling and analysis system is adopted to measure the thermal efficiency and $\mathrm{CO}$ emission.
According to CNS standard [17], the variations of water temperature versus time were recorded by a $K$-type thermocouple, which is arranged at the midpoint of the water depth. The thermal efficiency of a gas burner is defined as the percentage of the thermal input transferred to the loading water, which can be determined by (1). In other words, it can be calculated by measuring the elapsed time for a standard load of water $(4.4 \mathrm{~kg})$ to be heated through a temperature rise of $50^{\circ} \mathrm{C}$ from the initial temperature (room temperature) and the corresponding fuel (LPG) consumed:

$$
\eta=\frac{m \times C_{p} \times \Delta T}{Q \times \mathrm{HHV}} \times 100 \%,
$$

where $m(\mathrm{~kg})$ denotes the mass of water, $C_{P}\left(\mathrm{~kJ} / \mathrm{kg}^{\circ}{ }^{\circ} \mathrm{C}\right)$ is the specific heat at constant pressure of water, $\Delta T$ equals $50^{\circ} \mathrm{C}, \mathrm{Q}$ $\left(\mathrm{m}^{3}\right)$ represents the consumption of $\mathrm{LPG}$, and $\mathrm{HHV}\left(\mathrm{kJ} / \mathrm{m}^{3}\right)$ designates the higher heating value of LPG.

The CO emissions are measured by a semicircular sampling tube that is located at $1 / 3$ of the loading height from the top and $3 \mathrm{~mm}$ away from the edge of the loading vessel. A gas analyzer (Testo 350-XL) is used to continuously measure the concentrations of combustion products. The $\mathrm{CO}$ emission resulting from incomplete combustion is greatly taken into consideration because of the hazard of $\mathrm{CO}$ poisoning. In this study, $\mathrm{CO}^{*}$ is employed to designate the $\mathrm{CO}$ emission, which is defined by the following equation [17]:

$$
\mathrm{CO}^{*}=\mathrm{CO}_{a} \times \frac{\mathrm{O}_{2 t}}{\mathrm{O}_{2 t}-\mathrm{O}_{2 a}},
$$

where $\mathrm{CO}^{*}$ is the theoretical $\mathrm{CO}$ concentration of dry combustion product, $\mathrm{CO}_{a}$ is the measured $\mathrm{CO}$ concentration, $\mathrm{O}_{2 t}$ is the theoretical $\mathrm{O}_{2}$ concentration in dry air, and $\mathrm{O}_{2 a}$ is the measured $\mathrm{O}_{2}$ concentration.

\section{Results and Discussion}

Variations of thermal efficiency and $\mathrm{CO}$ emission versus swirl angle at a fixed thermal input $4.75 \mathrm{~kW}$ for the open flame and semiconfined flame at fuel supply pressure $P=280 \mathrm{~mm} \mathrm{H}_{2} \mathrm{O}$ and loading height $L=2.5 \mathrm{~cm}$ are shown in Figures 6 and 7, respectively. As can be seen in Figures 6 and 7, for both open flames and semiconfined flames, the swirl flow burner gives higher thermal efficiency than the radial flow burner. As swirl angle is increased from $0^{\circ}$ to $56^{\circ}$, the latter gives higher thermal efficiency than the former by at least $2 \%$ for the open flames (Figure 6) and semiconfined flames (Figure 7). The improvement in thermal efficiency of the swirl flow burner is mainly achieved by the increased heat transfer coefficient at the vessel bottom resulting from prolonged residence time of the combustion products in the vicinity of the vessel bottom [15]. Moreover, the enhancement in flow mixing and combustion process can be achieved owing to the rotating flow field [15]. Figures 6 and 7 also show that the addition of the shield yields a great increase in thermal efficiency, about $4-5 \%$, for the same burner with swirl flow or radial flow at a fixed thermal input. The reason is that, as the dispersion of the flame or flue gas into the surroundings can be delayed 


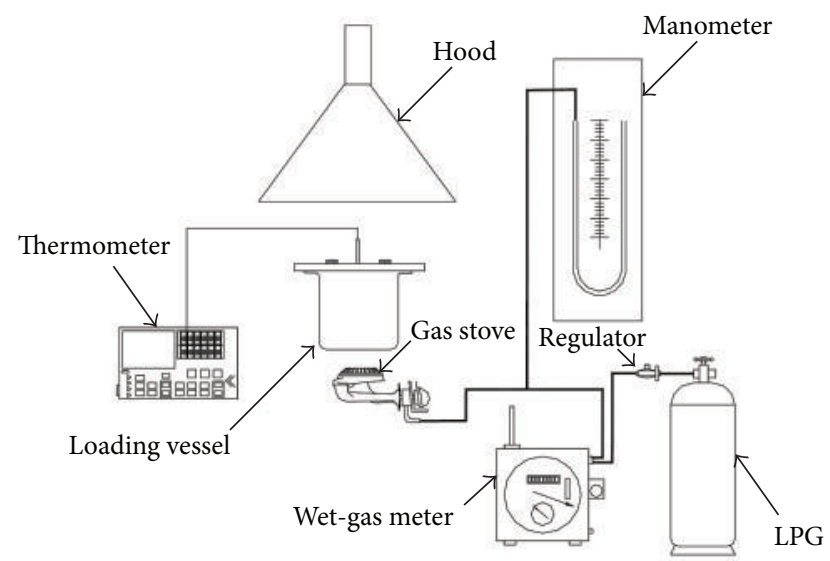

FIGURE 1: Schematic of the experimental apparatus.

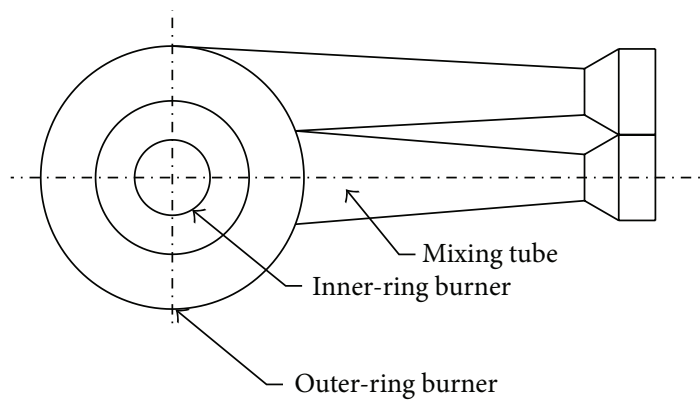

(a)

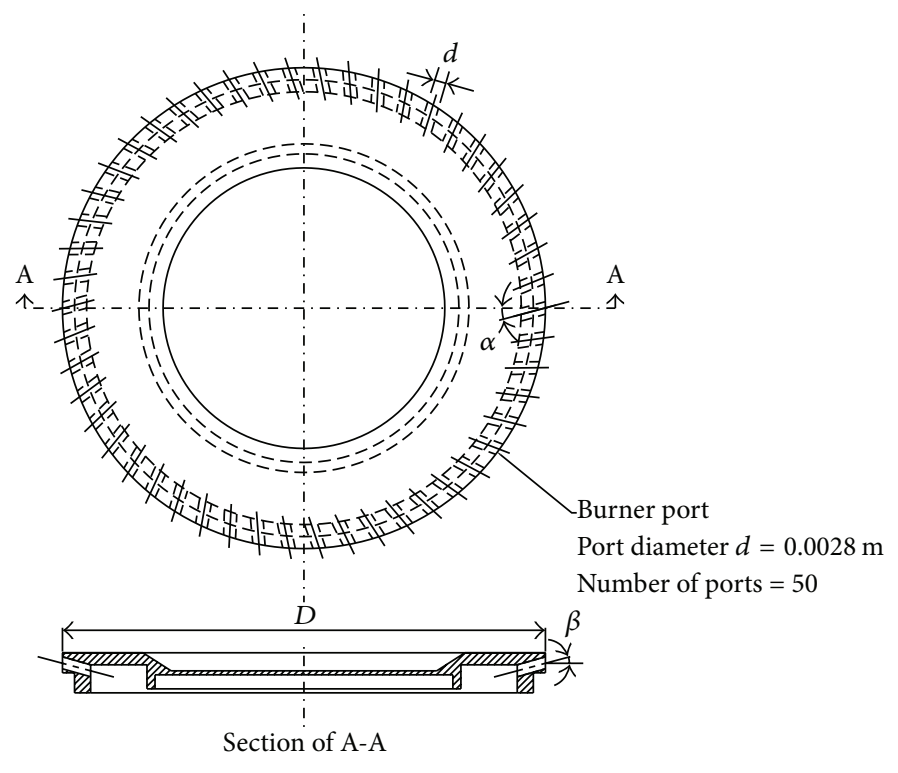

(b)

FIGURE 2: Schematic of (a) burner head and (b) outer-ring swirl flow burner.

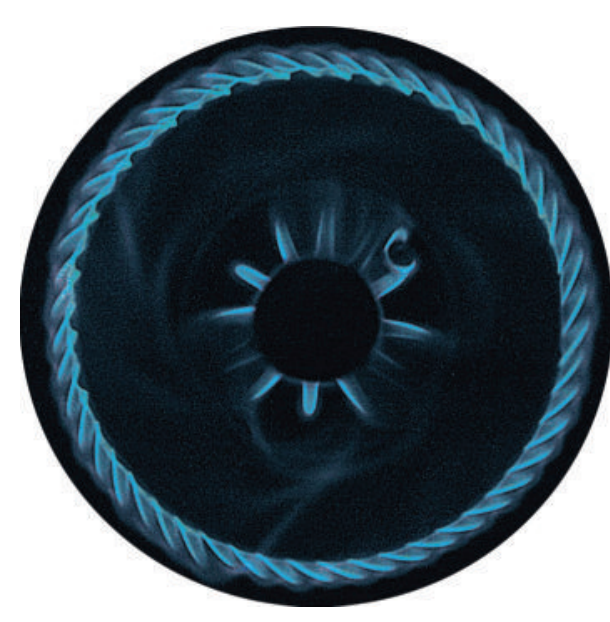

(a)

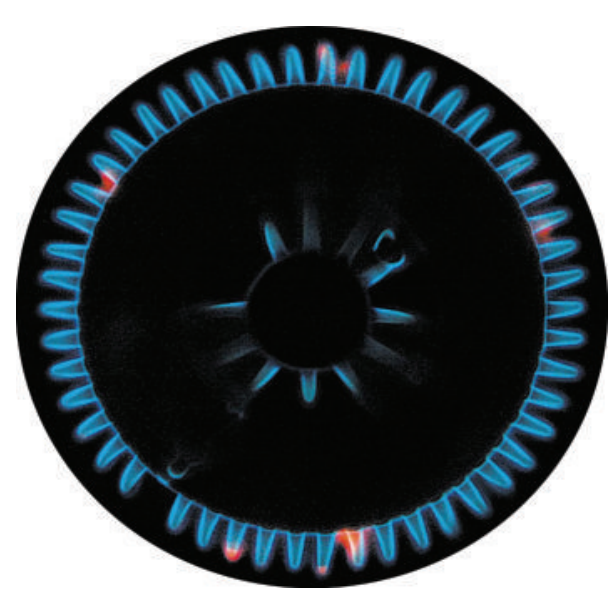

(b)

FIGURE 3: Top view of (a) swirling flame burner and (b) nonswirling flame burner. 


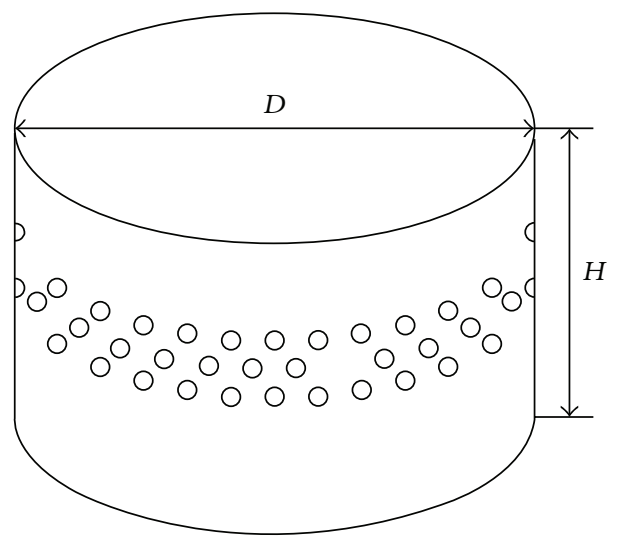

Diameter of circular shield (D): $0.32 \mathrm{~m}$

Thickness of circular shield $(t): 0.0008 \mathrm{~m}$

Height of circular shield $(H): 0.11 \mathrm{~m}$

Number of round holes $(N): 15212$

Diameter of round hole $\left(D_{H}\right): 0.00155 \mathrm{~m}$

FIGURE 4: Schematic diagram of the circular shield.

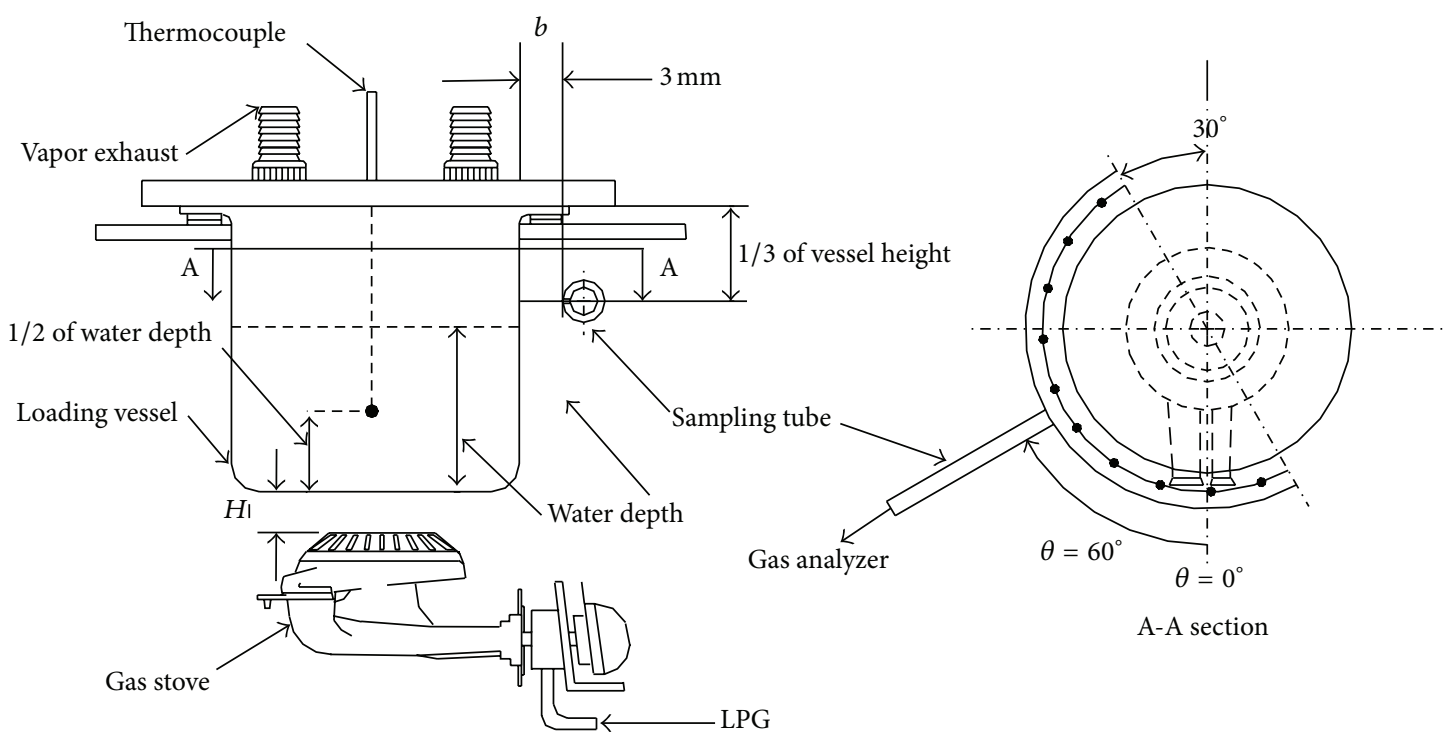

FIGURE 5: Schematic diagram of the sampling and analysis system.

by the shield, a significant improvement of thermal efficiency can be achieved.

Furthermore, it can be seen from the results of Figures 6 and 7 that the swirl flow burner produces slightly higher $\mathrm{CO}$ emission than the radial flow burner at fixed values of thermal input and loading height. The port shape of the swirl flow burner is elliptic, different from that of the radial flow burner, which is circular, along the circumference of the outer-ring burner. Therefore, the swirl flow burner has relatively narrow port spacing leading to slightly lower secondary aeration as compared with the radial flow burner. In comparison to the radial flow burner, however, enhanced mixing, extended residence time, and higher heat transfer coefficient between the flame and the thermal load of the swirl flow burner greatly prevent incomplete combustion and eventually lead to only a relatively small increase in $\mathrm{CO}$ emissions.

Since loading height is an important design parameter, particular emphasis is now put on the impact of loading height $(L)$ on thermal efficiency and $\mathrm{CO}$ emissions. In addition, inclination angle $(\beta)$ is a significant port design parameter strongly affecting burner performance. Figures 8 and 9 demonstrate the influence of the inclination angle $(\beta)$ and loading height $(L)$ on the thermal efficiency and $\mathrm{CO}$ emission at a thermal input $4.75 \mathrm{~kW}$ for the open flame, respectively. Meanwhile, Figures 10 and 11 show the influence of the inclination angle $(\beta)$ and loading height $(L)$ 


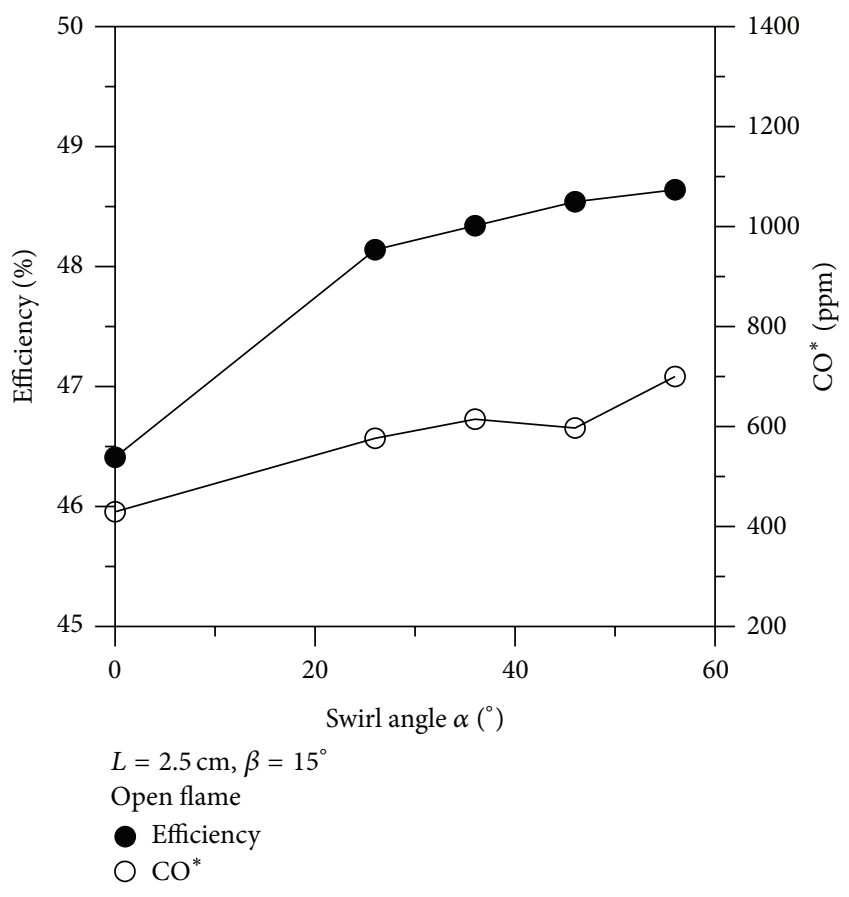

Figure 6: Effect of $\alpha$ on $\eta$ and CO for open flames.

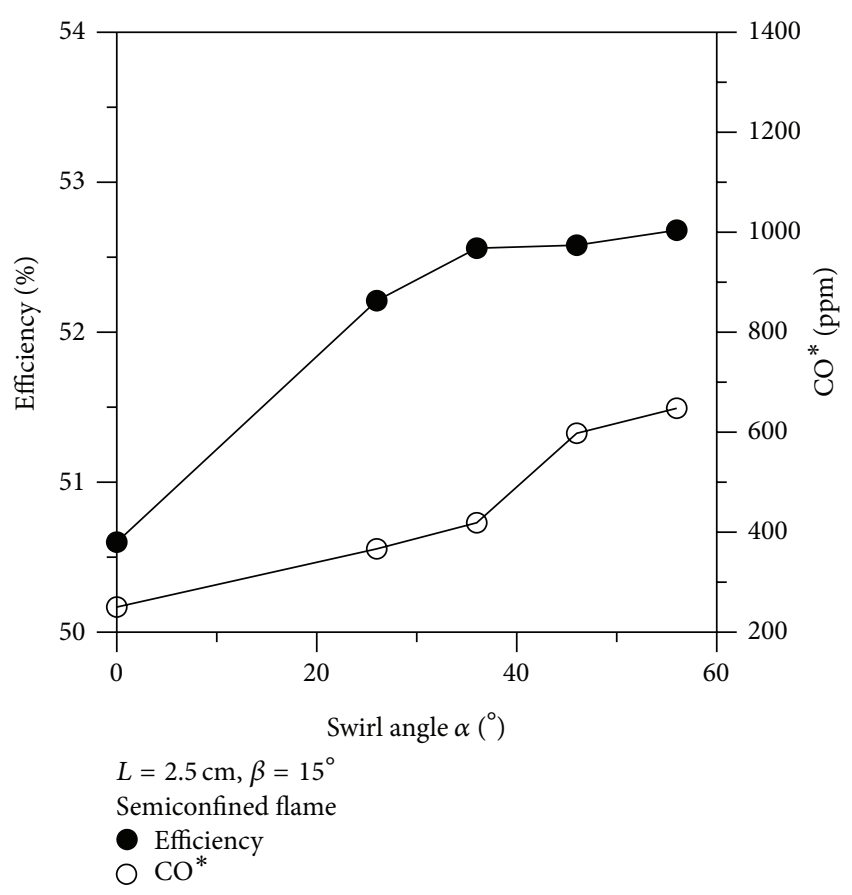

FIGURE 7: Effect of $\alpha$ on $\eta$ and CO for semiconfined flames.

on the thermal efficiency and $\mathrm{CO}$ emission for the semiconfined flame, respectively. It can be found from the results of Figures 8-11 that an increase in loading height leads to a decrease in thermal efficiency and a reduction in $\mathrm{CO}$ emissions. At a higher loading height, the flame and combustion gases are cooled to a greater extent owing to flow mixing with ambient cool air before they contact the loading

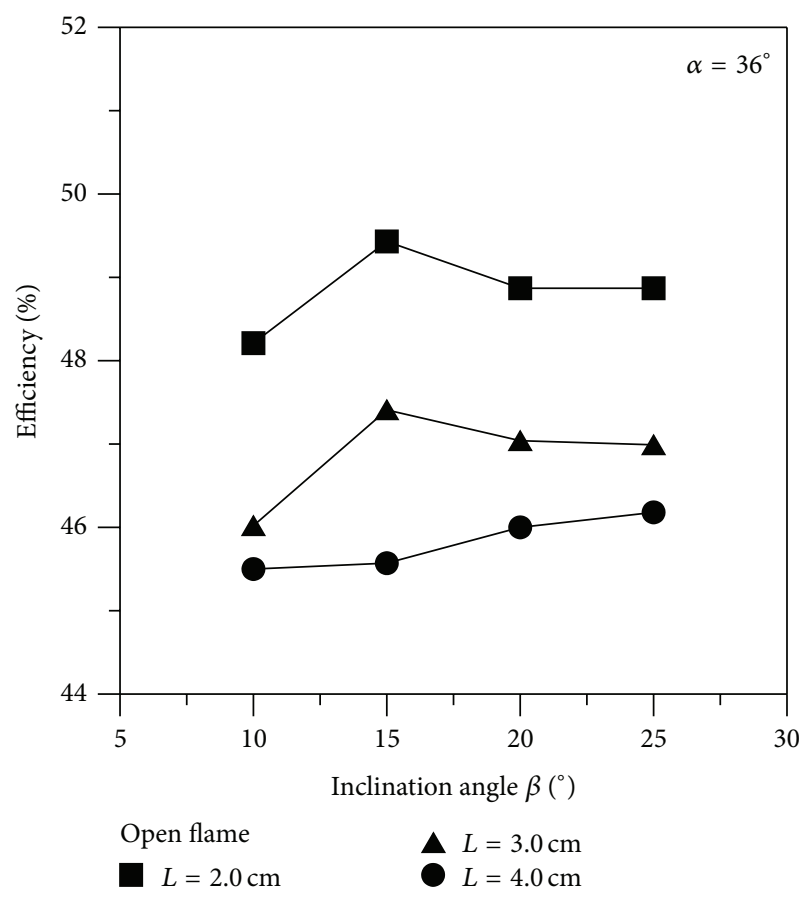

FIGURE 8: Effects of $\beta$ and $L$ on $\eta$ for open flames.

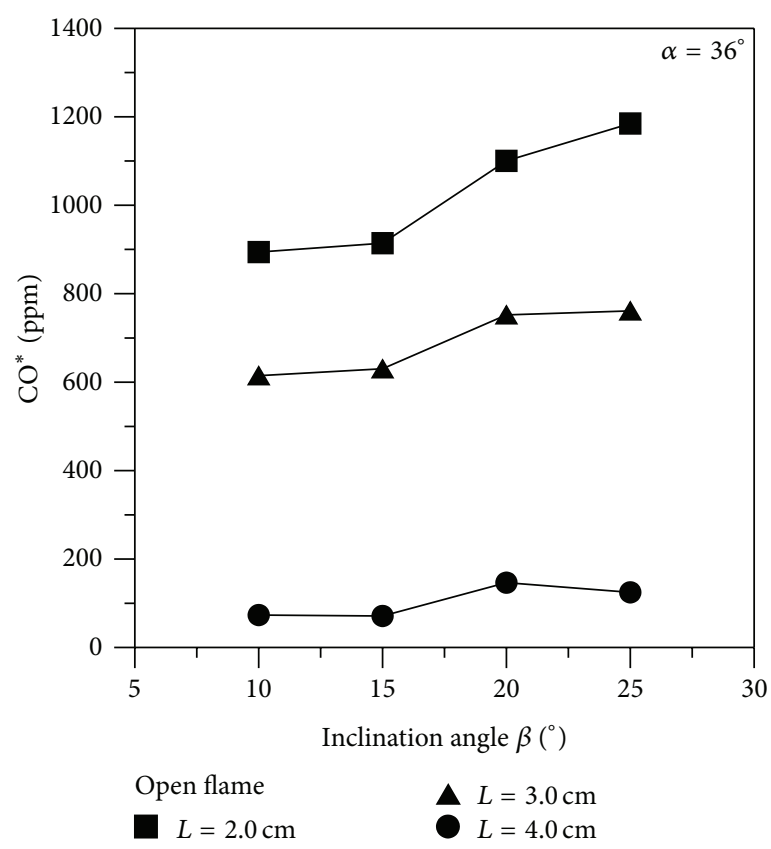

Figure 9: Effects of $\beta$ and $L$ on CO for open flames.

vessel. Therefore, the temperature gradient for heat transfer is decreased.

On the other hand, as the loading height decreases, the slope of water temperature versus time becomes steeper due to an increase in flame impingement on the load such that a smaller amount of fuel consumption is required to heat up a load and higher thermal efficiency is achieved, as shown in Figures 8 and 10. Meanwhile, as loading height decreases, 


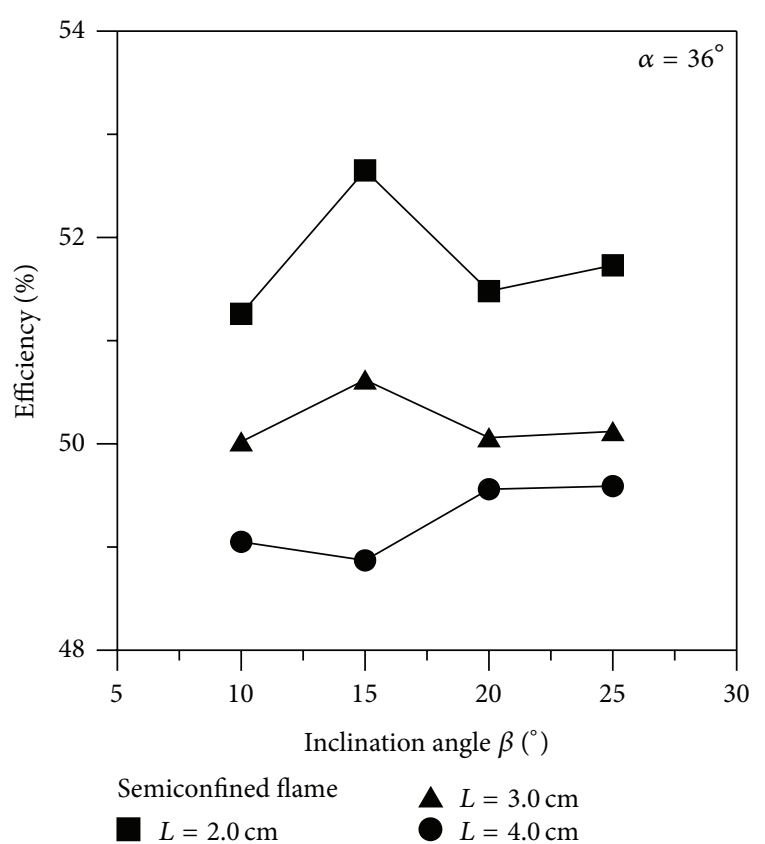

FIgURE 10: Effects of $\beta$ and $L$ on $\eta$ for semiconfined flames.

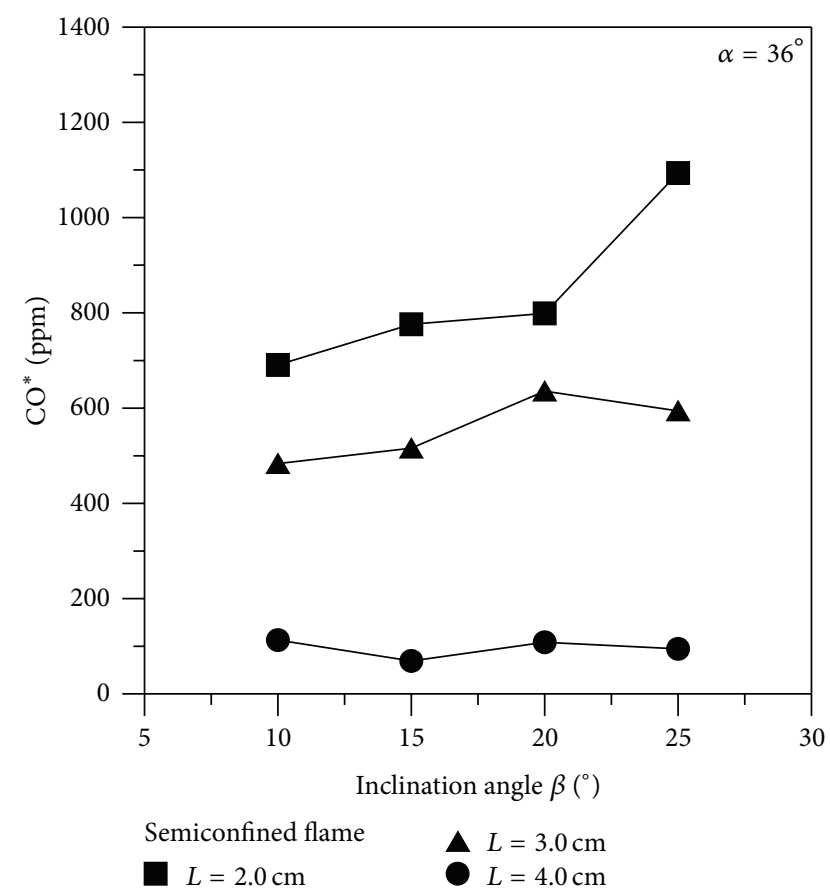

FIGURE 11: Effects of $\beta$ and $L$ on CO for semiconfined flames.

a larger amount of postflame gases is cooled as a result of contacting with the loading vessel. Consequently, incomplete combustion increases because of increased flame quenching by the load, leading to an increase in $\mathrm{CO}$ emission, as shown in Figures 9 and 11. These characteristics have also been observed by Ko and Lin [6].

It is also found from the results of Figures 8-11 that, for a lower loading height ( $L=2$ or $3 \mathrm{~cm}$ ), the highest efficiency occurs at $\beta=15^{\circ}$. On the other hand, at a higher loading height $(L=4 \mathrm{~cm})$, thermal efficiency increases with inclination angle $\beta$. The reason is that a greater inclination angle $\beta$ corresponds to a longer flame and thus the temperature gradient for heat transfer is increased. Moreover, as can be seen, at a lower loading height $(L=2$ or $3 \mathrm{~cm})$, the $\mathrm{CO}$ emissions increase with an increase in inclination angle because of increased quenching (incomplete combustion) by the load, while, at a higher loading height $(L=4 \mathrm{~cm})$, the $\mathrm{CO}$ emission is quite low and only slightly influenced by the inclination angle.

\section{Conclusions}

In this study, a domestic gas burner with swirling flames was adopted to investigate the significant parameters, namely, swirl angle, inclination angle, loading height, and shielded flame (semiconfined flame), affecting the burner performance. Concluding remarks are addressed as follows.

(1) As swirl angle is increased from $0^{\circ}$ to $56^{\circ}$, the latter gives higher thermal efficiency than the former by at least $2 \%$ for both open flames and semiconfined flames.

(2) Generally, the increase in loading height results in a decrease in thermal efficiency and a reduction in $\mathrm{CO}$ emissions. The opposite holds for the decrease in loading height.

(3) For a lower loading height ( $L=2$ or $3 \mathrm{~cm}$ ), the highest efficiency occurs at the inclination angle $\beta=15^{\circ}$, and the $\mathrm{CO}$ emission increases with an increase in inclination angle. On the other hand, at a higher loading height $(L=4 \mathrm{~cm})$, thermal efficiency increases with inclination angle $\beta$ but the $\mathrm{CO}$ emission is quite low and only slightly influenced by the inclination angle.

(4) The addition of the shield yields a great increase in thermal efficiency, about $4-5 \%$, and a decrease in CO emissions for the same burner (swirl flow or radial flow).

\section{Conflict of Interests}

The authors declare that there is no conflict of interests regarding the publication of this paper.

\section{Acknowledgments}

The authors greatly appreciate the financial support of this work by the Industrial Technology Research Institute and the National Science Council, Taiwan.

\section{References}

[1] R. Junus, J. F. Stubington, and G. D. Sergeant, "Effects of design factors on emissions from natural gas cooktop burners," International Journal of Environmental Studies, vol. 45, no. 2, pp. 101-121, 1994. 
[2] J. F. Stubington, G. Beashel, T. Murphy, R. Junus, P. J. Ashman, and G. D. Sergeant, "Emissions and efficiency from production cooktop burners firing natural gas," Journal of the Institute of Energy, vol. 67, no. 473, pp. 143-155, 1994.

[3] P. J. Ashman, R. Junus, J. F. Stubington, and G. D. Sergeamt, "The effects of load height on the emissions from a natural gas-fired domestic cooktop burner," Combustion Science and Technology, vol. 103, pp. 283-298, 1994.

[4] A. Y. Wagner, H. Livbjerg, P. G. Kristensen, and P. Glarborg, "Particle emissions from domestic gas cookers," Combustion Science and Technology, vol. 182, no. 10, pp. 1511-1527, 2010.

[5] Y. C. Ko, S. S. Hou, and T. H. Lin, "Laminar diffusion flames in a multiport burner," Combustion Science and Technology, vol. 177, no. 8, pp. 1463-1484, 2005.

[6] Y. C. Ko and T. H. Lin, "Emissions and efficiency of a domestic gas stove burning natural gases with various compositions," Energy Conversion and Management, vol. 44, no. 19, pp. 3001$3014,2003$.

[7] S. S. Hou and Y. C. Ko, "Effects of heating height on flame appearance, temperature field and efficiency of an impinging laminar jet flame used in domestic gas stoves," Energy Conversion and Management, vol. 45, no. 9-10, pp. 1583-1595, 2004.

[8] S. S. Hou and Y. C. Ko, "Influence of oblique angle and heating height on flame structure, temperature field and efficiency of an impinging laminar jet flame," Energy Conversion and Management, vol. 46, no. 6, pp. 941-958, 2005.

[9] S. S. Hou, "Improvement in thermal efficiency and reduction in $\mathrm{CO}$ emissions of domestic gas burners via various heat transfer mechanisms," Final Report for ITRI, Industrial Technology Research Institute, Hsinchu, Taiwan, 2005 (Chinese).

[10] A. Tamir, I. Elperin, and S. Yotzer, "Performance characteristics of a gas burner with a swirling central flame," Energy, vol. 14, no. 7, pp. 373-382, 1989.

[11] A. Tamir, "A swirling-flame combustor for lean mixtures," Combustion Science and Technology, vol. 90, no. 1-4, pp. 193209, 1993.

[12] S. Jugjai, S. Tia, and W. Trewetasksorn, "Thermal efficiency improvement of an LPG gas cooker by a swirling central flame," International Journal of Energy Research, vol. 25, no. 8, pp. 657674, 2001.

[13] S. Jugjai and N. Rungsimuntuchart, "High efficiency heatrecirculating domestic gas burners," Experimental Thermal and Fluid Science, vol. 26, no. 5, pp. 581-592, 2002.

[14] H. R. N. Jones, The Application of Combustion Principles to Gas Burner Design, British Gas, 1989.

[15] S. S. Hou, C. Y. Lee, and T. H. Lin, "Efficiency and emissions of a new domestic gas burner with a swirling flame," Energy Conversion and Management, vol. 48, no. 5, pp. 1401-1410, 2007.

[16] V. Shtern, A. Borissov, and F. Hussain, "Temperature distibution in swirling jets," International Journal of Heat and Mass Transfer, vol. 41, no. 16, pp. 2455-2467, 1998.

[17] "The method of test for gas burning appliances of domestic use," CNS General no. 13605, The Chinese National Standard, 1995. 

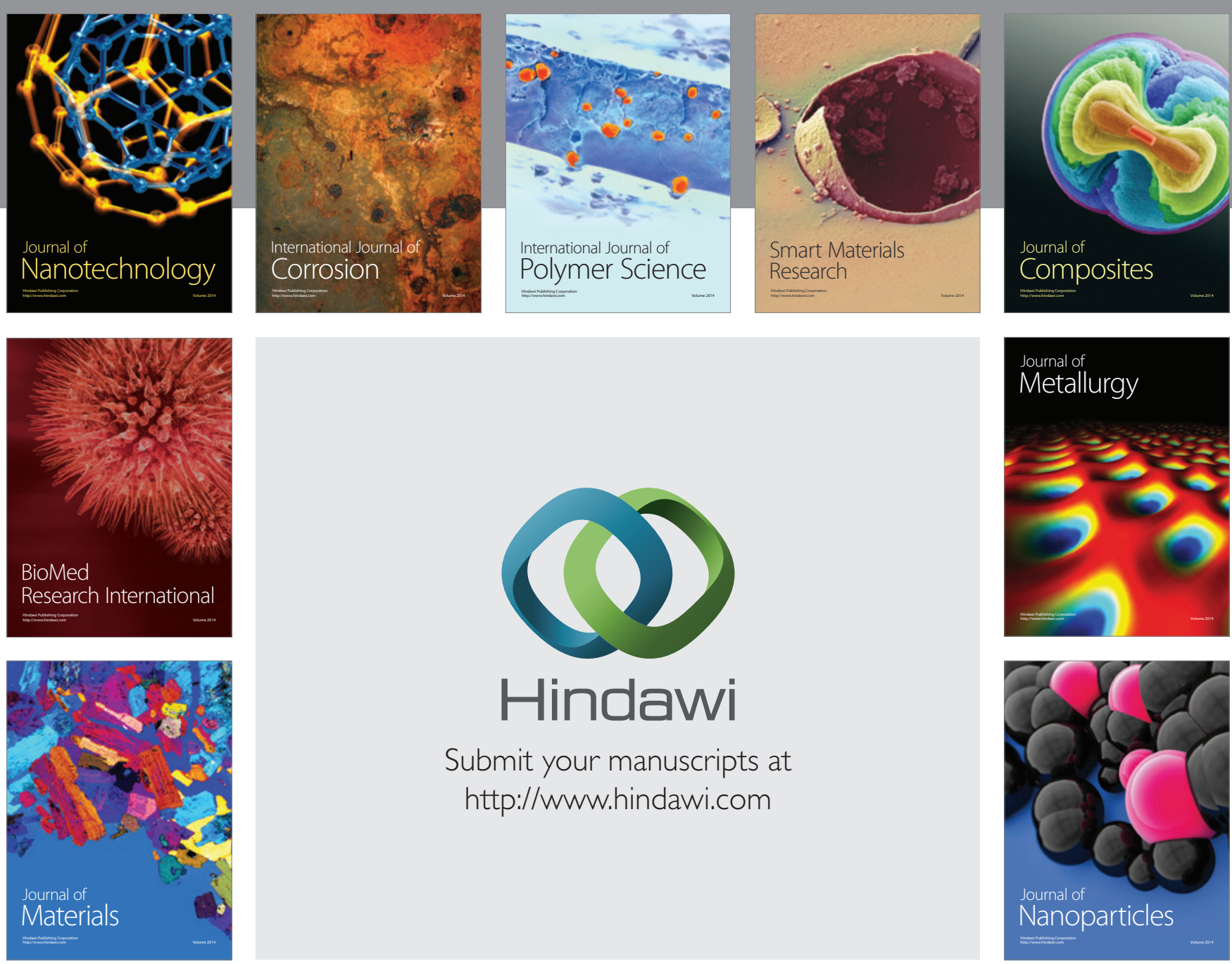

Submit your manuscripts at http://www.hindawi.com
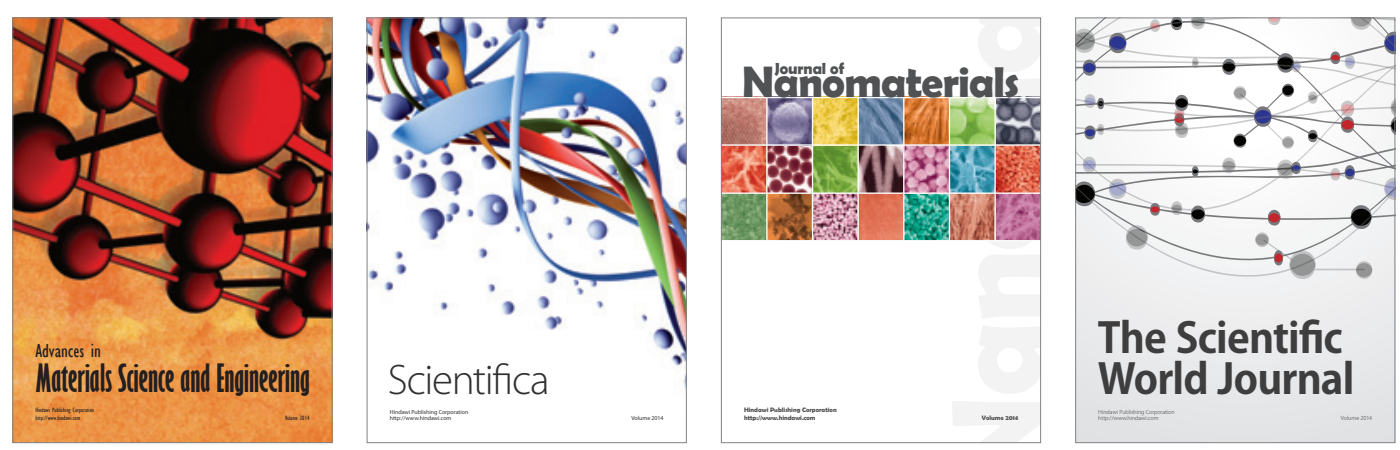

\section{The Scientific World Journal}
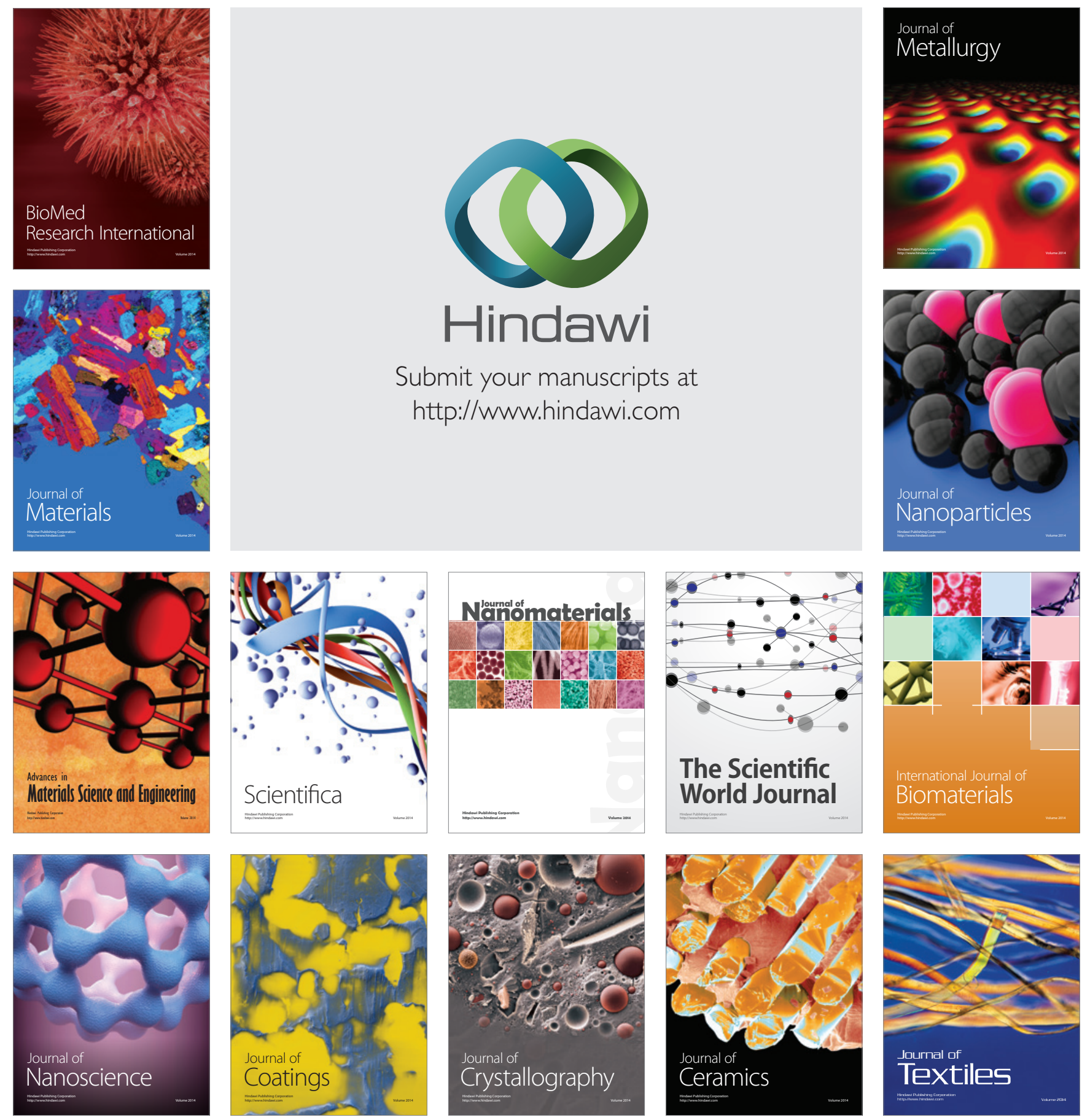